\title{
Unilateral acute posterior multifocal placoid pigment epitheliopathy in a convalescent COVID-19 patient
}

\author{
Francisco Olguín-Manríquez ${ }^{1,7^{*}}$ (D) Linda Cernichiaro-Espinosa², Arturo Olguín-Manríquez ${ }^{3}$, \\ Rebeca Manríquez-Arias ${ }^{4}$, Erick Omar Flores-Villalobos ${ }^{5}$ and Perla Ayumi Kawakami-Campos ${ }^{6}$
}

\begin{abstract}
Background: To report a case of unilateral acute posterior multifocal placoid pigment epitheliopathy (APMPPE) in a Hispanic convalescent COVID-19 female patient.

Case presentation

A 35-year-old Hispanic female with exposure to the severe acute respiratory syndrome coronavirus 2 (SARS-CoV-2) was evaluated due to unilateral visual loss. Ophthalmic examination and diagnostic tests were consistent with APMPPE.
\end{abstract}

Discussion: Ocular changes can be observed in patients with COVID-19. A complete ophthalmic evaluation must be performed in patients with low vision after SARS-CoV-2 infection.

Keywords: Acute posterior multifocal placoid pigment epitheliopathy, Severe acute respiratory syndrome coronavirus 2, Coronavirus disease 2019

\section{Introduction}

In February 2020, the International Committee on Taxonomy of Viruses (ICTV) announced the severe acute respiratory syndrome coronavirus 2 (SARS-CoV-2) as a new virus. This name was chosen because the virus is genetically related to the coronavirus responsible for the SARS outbreak of 2003. The World Health Organization (WHO) named this new disease as "COVID-19" in February 2020. The disease quickly reached the size of a pandemic on March 11, 2020, due to the speed and scale of the transmission [1].

There are basically 3 stages or phases in the natural history of COVID-19, regarding disease severity. The first

\footnotetext{
*Correspondence: francisco_olguinm@hotmail.com

${ }^{7}$ Retina Service, Oftal Unidad Médica, Av. Paseo de la Reforma 155,

Colonia Lomas de Chapultepec, Alcaldía Miguel Hidalgo, 11000 Mexico City, CP, Mexico

Full list of author information is available at the end of the article
}

phase is related to the onset of the disease and is generally characterized by the development of influenza-like symptoms from mild to moderate. Some individuals recover and some progress to the second phase. During the second phase, it is possible to detect pneumonialike symptoms. Depending on the severity of phase two, patients can improve, or worsen with the necessity of intubation and ventilation. The phase three is characterized by hyper inflammation and sepsis of lungs. Patients often require intensive care unit and most of them unfortunately cannot overcome the infection and eventually die [2].

Ocular manifestations in COVID-19 patients may include conjunctivitis, chemosis, and epiphora. Higher neutrophil counts, procalcitonin, C-reactive proteins, and lactate dehydrogenase are factors associated with such signs [3].

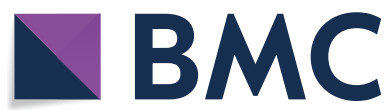

c The Author(s) 2021. This article is licensed under a Creative Commons Attribution 4.0 International License, which permits use, sharing, adaptation, distribution and reproduction in any medium or format, as long as you give appropriate credit to the original author(s) and the source, provide a link to the Creative Commons licence, and indicate if changes were made. The images or other third party material in this article are included in the article's Creative Commons licence, unless indicated otherwise in a credit line to the material. If material is not included in the article's Creative Commons licence and your intended use is not permitted by statutory regulation or exceeds the permitted use, you will need to obtain permission directly from the copyright holder. To view a copy of this licence, visit http://creativeco mmons.org/licenses/by/4.0/. The Creative Commons Public Domain Dedication waiver (http://creativecommons.org/publicdomain/ zero/1.0/) applies to the data made available in this article, unless otherwise stated in a credit line to the data. 
Posterior segment manifestations may include retinal hemorrhages, cotton wool spots, and dilated retinal vessels. Higher veins diameter has been positively correlated with disease severity [4]. Interestingly, SARS-CoV-2 infects endothelial cells [5]. Hyper-reflective lesions at the level of inner plexiform and ganglion cell layers have been documented in twelve patients examined 11-33 days after the onset of COVID-19 symptoms [6]. Vitritis and disruption of the ellipsoid zone and hyperreflective lesions at the level of inner plexiform and ganglion cell layers have also been reported [7].

We present a case of a convalescent COVID-19 female patient with acute posterior multifocal placoid pigment epitheliopathy (APMPPE).

\section{Case presentation}

A 35-year-old Hispanic female presented blurred vision, central scotoma and photopsia in her right eye. She had experienced fever, headaches and myalgia 6 weeks before initial consultation. The patient had past history of Diabetes mellitus diagnosed 3 years before, and good glucose control was obtained with insulin. She tested positive for SARS-Cov-2 IgG antibody 2 weeks before ophthalmic examination. Previous ocular history was unremarkable.

A complete ophthalmological exam was performed. Best-corrected visual acuity (BCVA) was $20 / 400$ in the right eye (RE) and 20/20 in the left eye (LE). Biomicroscopy of the anterior segment, pupillary reflexes, and intraocular pressure were normal in both eyes (OU). At fundus examination, multiple yellow-white placoid lesions were evident at the posterior pole in the RE (Fig. 1a). LE posterior segment was unremarkable (Fig. 1b). Fluorescein Angiography (FA) showed early hypofluorescence at the foveal lesions with late hyperfluorescence of all lesions (Fig. 1c-d). Fundus autofluorescence (FAF) revealed hypo-autofluorescence of all lesions surrounded by a hyper-autofluorescent halo (Fig. 1f). Optical Coherence Tomography (OCT) scans across the placoid lesions showed hyper-reflective material at the level of the outer retinal layers and disruption at the interdigitation zone in the foveal depression (Fig. 1h-i).

Complete blood count with differential and tests for infectious disease (tuberculosis, syphilis, and toxoplasmosis) were requested-the results obtained were negative. Routine blood tests were normal.

Based on imaging and clinical features, the patient was diagnosed with APMPPE.

\section{Discussion}

More commonly ocular manifestations have been reported in patients with COVID-19 such as conjunctivitis, chemosis, and epiphora in patients with severe systemic disease or abnormal findings on blood tests [3].
Our patient started with unilateral macular dysfunction 6 weeks after the onset of influenza-like symptoms. Laboratory tests found positive IgG antibody for SARS$\mathrm{CoV}-2$, showing serological evidence of past infection for COVID-19. Fundus photographs, FA, FAF, and OCT findings correlate well with previous descriptions of APMPPE lesions $[14,15]$. APMPPE is an acute-onset inflammatory disease that affects the choriocapillaris, RPE, and outer retina. Numerous, yellow, creamy colored placoid lesions are seen in the posterior pole and are not seen anterior to the equator [13].

Up to one third of APMPPE cases worldwide have been described as related to a viral prodromic period. While viruses as type five Adenovirus and B4 Coxsackievirus have been typically associated with white dot syndromes, there have been reports of post vaccination disease. Its cause has not been clearly elucidated yet since the incidence of these syndromes is very low. However, Coxsackie antibody titers in acute and treated cases seem to correlate in some series [16].

Using multimodal imaging in APMPPE, some authors have found choroidal inflammation as a preceding and necessary factor for RPE, and subsequent damage in cones [16]. This choroidal inflammation may be generated solely by the entry of SARS-CoV-2 via the angiotensin-converting enzyme 2 receptor (ACE) in the endothelium. The presence and abundance of this receptor has already been found higher in COVID-19 fatal cases compared to controls [17]. In these patients the accumulation of mononuclear cells and neutrophils in the lumen and intima of choriocapillaris may prove the viral trigger for white dot syndromes.

Detection of SARS-CoV-2 has been confirmed by Realtime reverse transcriptase-polymerase chain reaction (RT-PCR) in human retinal biopsies (RB) of deceased COVID-19 patients. Although ocular symptoms or changes in the posterior segment were not analyzed in these patients, important information about virus presence in the retina was confirmed [8].

Experimental coronavirus retinopathy (ECOR) occurs after intravitreal inoculation of murine coronavirus (M-CoV, JHM strain) in BALB/c and CD-1 mice. In $\mathrm{BALB} / \mathrm{c}$ mice, JHM strain induces a biphasic retinal disease characterized by retinal vasculitis observed one to seven days after inoculation (early phase) followed by retinal degeneration in the absence of inflammation (second phase) [9]. The virus can be observed intracellularly within vacuoles and extracellularly at the plasma membrane. [10] The reduction in the interphotoreceptor retinoid-binding protein (IRBP) is a proposed mechanism of retinal damage observed in ECOR models. IRBP is synthesized by retinal photoreceptor cells and acts as an important transport of retinoids between photoreceptors 

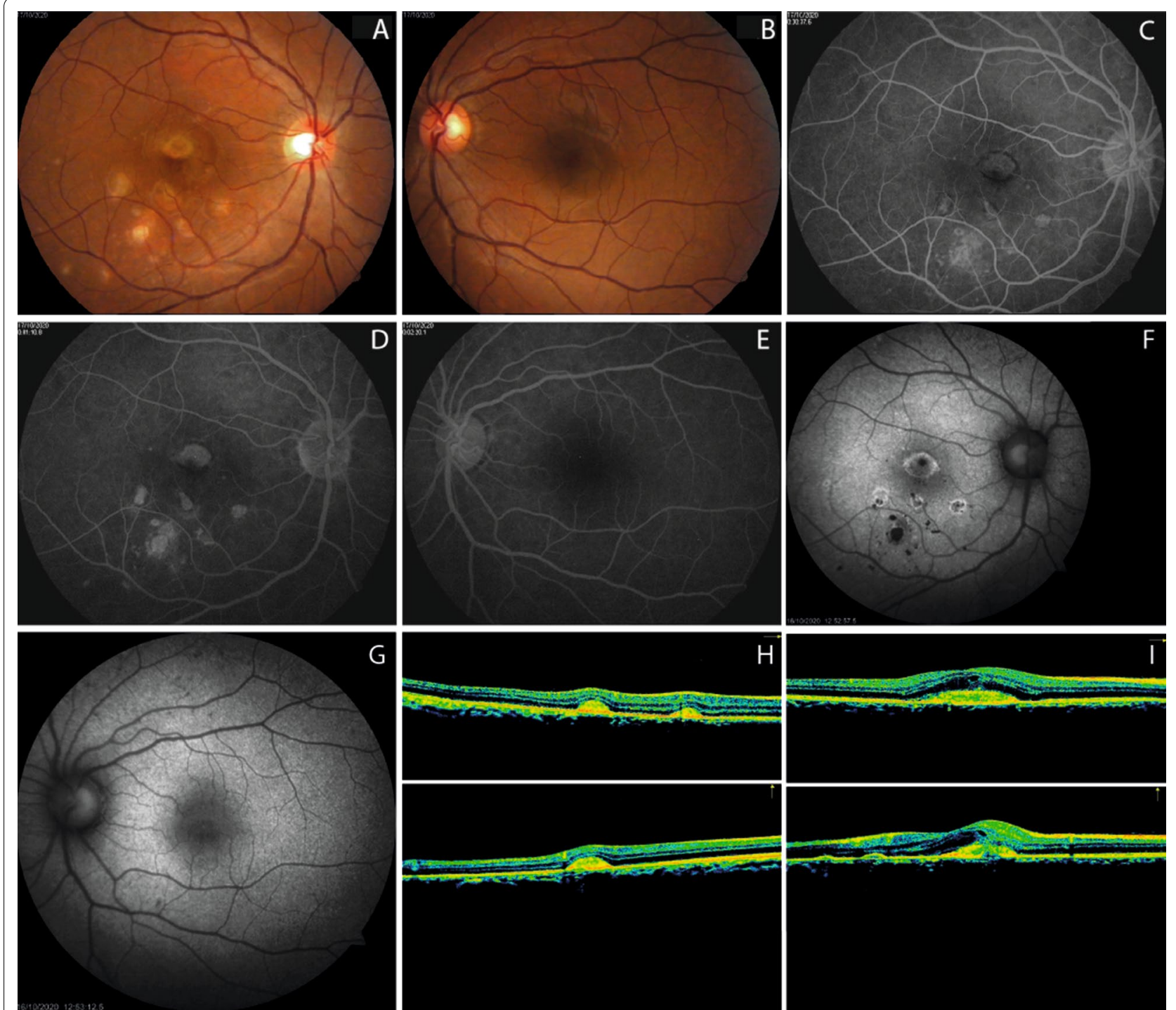

Figure. 1 Fundus multimodal imaging of a patient with serological evidence of SARS-CoV-2 exposure. A, B: color fundus photographs showing multiple yellow-white placoid lesions involving the fovea in the right eye. Left eye posterior segment is unremarkable. C-D: fluorescein angiography demonstrates early hypofluorescence with hyperfluorescent staining of all lesions. E: normal fluorescein angiogram in the LE. F: fundus autofluorescence showing hypoautofluorescent lesions surrounded by a hyperautofluorescent halo in the right eye. G: fundus autofluorescence shows isoautofluorescence in the left eye. $\mathbf{H}-\mathbf{l}$ : cross-sectional optical coherence tomography (OCT) scans in extrafoveal lesions demonstrate hyper-reflective material at the level of the outer retinal layers. Disruption of the interdigitation zone and hyper-reflective material is observed at the foveal depression

and RPE. The coronavirus could interfere with normal synthesis and/or secretion of IRBP through the rough endoplasmic reticulum and Golgi complex of the photoreceptor cell. Thus, the resultant retinoid excess in the photoreceptor can be toxic [11]. Further investigations found a correlation between higher levels of Interferon- $\Upsilon$ $\left(\mathrm{IFN}_{\Upsilon}\right.$ ) and retinal damage in BALB/c mice after inoculation of JHM strain in the vitreous cavity [12].

There is uncertainty if retinal changes (micro hemorrhages, cotton wool spots) or changes on OCT (hyper reflective dots at the level of inner plexiform or ganglion cell layers) appear days or weeks after the onset of COVID-19 and its relation to the severity of the disease or symptoms $[4,6,7]$.

To the best of our knowledge, this is the first case of APMPPE in a convalescent COVID-19 patient. Understanding of the physiopathology is still needed 15. 


\begin{abstract}
Abbreviations
APMPPE: Acute posterior multifocal placoid pigment epitheliopathy; WDS: White dot syndromes; COVID-19: Coronavirus disease; WHO: World health organization; RPE: Retinal pigment epithelium; OCT: Optical coherence tomography; FAF: Fundus autofluorescence; FA: Fluorescein angiography; RE: Right eye; LE: Left eye; OU: Both eyes; IRBP: Interphotoreceptor retinoidbinding protein.
\end{abstract}

\section{Acknowledgements}

Not applicable.

\section{Authors' contributions}

FOM made substantial contributions to conceptualization, design, and the acquisition of data. LCE, EOFV, AOM, RMA contributed by writing up the manuscript. LCE, PAKC analyzed and interpreted the patient images. All authors read and approved the final manuscript.

\section{Funding}

Oftal Unidad Médica and COFAE provided their equipment for image acquisition.

\section{Availability of data and materials}

The data sets used and analyzed during the current study are available from the corresponding author on reasonable request.

\section{Declarations}

\section{Ethics approval and consent to participate}

Informed consent for publication of clinical details and/or images was obtained from the patient. Ethics approval is not applicable.

\section{Consent for publication}

Written informed consent was acquired.

\section{Competing interests}

The authors declare that they have no competing interests.

\section{Author details}

${ }^{1}$ Retina Department, Oftal Unidad Médica, Mexico city, Mexico. ${ }^{2}$ Retina Department, Asociación Para Evitar La Ceguera en México (APEC), Mexico City, Mexico. ${ }^{3}$ Cornea and Anterior Segment Department, Oftal Unidad Médica, Pachuca de Soto, Hidalgo, Mexico. ${ }^{4}$ General Ophthalmologist, Oftal Unidad Médica, Pachuca de Soto, Hidalgo, Mexico. ${ }^{5}$ Retina Department, Centro Oftalmológico de Alta Especialidad (COFAE), Pachuca de Soto, Hidalgo, Mexico.

${ }^{6}$ Retina Department, Instituto Nacional de Ciencias Médicas Y Nutrición "Salvador Zubirán", Mexico City, Mexico. ${ }^{7}$ Retina Service, Oftal Unidad Médica, Av. Paseo de la Reforma 155, Colonia Lomas de Chapultepec, Alcaldía Miguel Hidalgo, 11000 Mexico City, CP, Mexico.

Received: 28 November 2020 Accepted: 18 May 2021

Published online: 25 May 2021

\section{References}

1. World Health Organization, Naming the Coronavirus Disease (COVID-19) and the Virus That Causes It, 2020. https://www.who.int/emergencies/ diseases/novel-coronavirus-2019/technical-guidance/naming-the-coron avirus-disease-(covid-2019)-and-the-virus-that-causes-it. Accessed 5 May 2021.
2. Dos Santos WG. Natural history of COVID-19 and current knowledge on treatment therapeutic options. Biomed Pharmacother. 2020;129:110493. https://doi.org/10.1016/j.biopha.2020.110493.

3. Wu P, Duan F, Luo C, Liu Q, Qu X, Liang L, Wu K. Characteristics of ocular findings of patients with coronavirus disease 2019 (COVID-19) in Hubei province China. JAMA Ophthalmol. 2020;138(5):575-8. https://doi.org/10. 1001/jamaophthalmol.2020.1291.

4. Invernizzi A, et al. Retinal findings in patients with COVID-19: results from the SERPICO-19 study. EClinicalMedicine. 2020;27:100550. https://doi.org/ 10.1016/j.eclinm.2020.100550

5. Varga Z, Flammer AJ, Steiger $P$, et al. Endothelial cell infection and endotheliitis in COVID-19. Lancet. 2020;395(10234):1417-8. https://doi. org/10.1016/S0140-6736(20)30937-5.

6. Marinho PM, Marcos AAA, Romano AC, Nascimento H, Belfort R. Retinal findings in patients with COVID-19. Lancet. 2020;395(10237):1610. https://doi.org/10.1016/S0140-6736(20)31014-X

7. Zago Filho LA, Lima LH, Melo GB, Zett C, Farah ME. Vitritis and outer retinal abnormalities in a patient with COVID-19. Ocul Immunol Inflamm. 2020;28(8):1298-300. https://doi.org/10.1080/09273948.2020.1821898.

8. Casagrande M, Fitzek A, Püschel K, Aleshcheva G, Schultheiss H-P, Berneking L, Spitzer MS, Schultheiss M. Detection of SARS-CoV-2 in human retinal biopsies of deceased COVID-19 patients. Ocul Immunol Inflamm. 2020;28(5):721-5. https://doi.org/10.1080/09273948.2020.1770301.

9. Robbins SG, Hamel CP, Detrick B, Hooks JJ. Murine coronavirus induces an acute and long-lasting disease of the retina. Lab Invest. 1990;62(4):417-26.

10. Wang Y, Detrick B, Hooks JJ. Coronavirus (JHM) replication within the retina: analysis of cell tropism in mouse retinal cell cultures. Virology. 1993;193:124-37.

11. Robbins SG, Wiggert B, Kutty G, Chader GJ, Detrick B, Hooks JJ. Redistribution and reduction of interphotoreceptor retinoid-binding protein during ocular coronavirus infection. Invest Ophthalmol Vis Sci. 1992;33(1):60-7.

12. Hooks JJ, Wang $Y$, Detrick B. The critical role of IFN-gamma in experimental coronavirus retinopathy. Invest Ophthalmol Vis Sci. 2003;44(8):3402-8. https://doi.org/10.1167/iovs.02-1106.

13. Mirza RG, Moorthy RS, Jampol LM. Posterior uveitis of unknown causewhite spot syndromes. In: Yanoff M, Duker JS, editors. Ophthalmology. 4th ed. Philadelphia: Elsevier-Health Sciences Division; 2014. p. 778-87.

14. Goldenberg D, Habot-Wilner Z, Loewenstein A, Goldstein M. Spectral domain optical coherence tomography classification of acute posterior multifocal placoid pigment epitheliopathy. Retina. 2012;32(7):1403-10.

15. Gass JDM. Inflammatory diseases of the retina and choroid. In: Agarwal A, editor. Stereoscopic Atlas of Macular Diseases: Diagnosis and Treatment. 3rd ed. St Louis: CV. Mosby Co; 1987. p. 505-10.

16. Li AL, Palejwala NV, Shantha JG, O'Keefe G, Lee CS, Albini T, et al. Longterm multimodal imaging in acute posterior multifocal placoid pigment epitheliopathy and association with coxsackievirus exposure. PLoS ONE. 2020;15(8):e0238080. https://doi.org/10.1371/journal.pone.0238080.

17. Reinhold A, Tzankov A, Matter M, Mihic-Probst D, Scholl HP, Meyer P. Ocular pathology and occasionally detectable intraocular SARS-CoV-2 RNA in five fatal COVID-19 cases. Ophthalmic Res. 2021. https://doi.org/10.1159/ 000514573

\section{Publisher's Note}

Springer Nature remains neutral with regard to jurisdictional claims in published maps and institutional affiliations. 